\title{
Mobile Antimicrobial Resistance Genes in Probiotics
}

\author{
Adrienn Gréta Tóth ${ }^{1}\left(\mathbb{D}\right.$, István Csabai ${ }^{2} \mathbb{D}$, Maura Fiona Judge ${ }^{3}$, Gergely Maróti ${ }^{4,5}{ }^{\circledR}$, Ágnes Becsei ${ }^{2} \mathbb{1}$, \\ Sándor Spisák ${ }^{6}\left[\right.$ and Norbert Solymosi ${ }^{3, *(1)}$
}

1 Health Services Management Training Centre, Semmelweis University, 1125 Budapest, Hungary; tothadrienngreta@gmail.com

2 Department of Phyisics of Complex Systems, Eötvös Loránd University, 1117 Budapest, Hungary; csabai.istvan@gmail.com (I.C.); agi.becsei@gmail.com (Á.B.)

3 Centre for Bioinformatics, University of Veterinary Medicine Budapest, 1078 Budapest, Hungary; judgemf@tcd.ie

4 Institute of Plant Biology, Biological Research Center, 6726 Szeged, Hungary; marotig@seqomics.hu

5 Faculty of Water Sciences, University of Public Service, 6500 Baja, Hungary

6 Department of Medical Oncology, Dana-Farber Cancer Institute, Boston, MA 02115, USA;

sandor_spisak@dfci.harvard.edu

* Correspondence: solymosi.norbert@gmail.com; Tel.: +36-30-9347-069

check for updates

Citation: Tóth, G.A.; Csabai, I.; Judge, M.F.; Maróti, G.; Becsei, Á.; Spisák, S.; Solymosi, N. Mobile Antimicrobial Resistance Genes in Probiotics. Antibiotics 2021, 10, 1287. https: / / doi.org/10.3390/ antibiotics 10111287

Academic Editor: Jie Fu

Received: 12 August 2021

Accepted: 20 October 2021

Published: 21 October 2021

Publisher's Note: MDPI stays neutral with regard to jurisdictional claims in published maps and institutional affiliations.

\begin{abstract}
Even though people worldwide tend to consume probiotic products for their beneficial health effects on a daily basis, recently, concerns were outlined regarding the uptake and potential intestinal colonisation of the bacteria that they carry. These bacteria are capable of executing horizontal gene transfer (HGT) which facilitates the movement of various genes, including antimicrobial resistance genes (ARGs), among the donor and recipient bacterial populations. Within our study, 47 shotgun sequencing datasets deriving from various probiotic samples (isolated strains and metagenomes) were bioinformatically analysed. We detected more than 70 ARGs, out of which rpoB mutants conferring resistance to rifampicin, tet $(\mathrm{W} / \mathrm{N} / \mathrm{W})$ and potentially extended-spectrum beta-lactamase (ESBL) coding TEM-116 were the most common. Numerous ARGs were associated with integrated mobile genetic elements, plasmids or phages promoting the HGT. Our findings raise clinical and public health concerns as the consumption of probiotic products may lead to the transfer of ARGs to human gut bacteria.
\end{abstract}

Keywords: antimicrobial resistance; bacteriome; resistome; mobilome; probiotics

\section{Introduction}

Probiotics and probiotic products have gained a worldwide reputation and popularity in our everyday lives irrespective of cultural background, geographic location or social standards. Beneficial health effects assigned to probiotics have been reported in several studies [1]. What these studies have in common is that they state that microbes carried in probiotics must remain present in the intestinal tract for a shorter or longer period of time to exert the expected beneficial effects. Nevertheless, the success of colonisation depends on several factors, thus the certainty of its realisation varies from individual to individual [2]. Recently, however, the possibility of some unfavourable or sometimes even adverse effects of probiotic consumption have also been raised [3]. Several publications indicate that bacterial strains included in probiotic compounds, powders and capsules may contain antimicrobial resistance genes (ARGs) [4-7]. Recognising that ARGs may enter into the human body by food (e.g., probiotic products), studies on the genetic characteristics of microorganisms (including bacteria) used in the food chain have been recommended by European Food Safety Authority (EFSA) in recent years [8,9].

Genes, including ARGs of the probiotic bacteria, can be transmitted to bacteria within the intestinal tract of the consumers by horizontal gene transfer (HGT). If such ARGs are received by pathogenic bacteria, the efficacy of antibiotic therapy prescribed as medical 
intervention for the diseases they cause may lessen. HGT can take place by transformation, conjugation or transduction. All these processes have one important property in common, namely, a DNA fragment getting introduced to a recipient cell. Apart from transformation, by which any gene can be taken up by the bacterium from its environment, the routes of HGT require special active delivery processes. By conjugation, cell-to-cell contact provides the opportunity for a copy of a plasmid to translocate to a recipient bacterium [10]. In contrast, transduction negates the necessity for cell-to-cell contact, as in this case bacteriophages act as a conduit for shuttling genes among bacteria [11]. The genetic environment of the genes, possibly ARGs, involved in the transfer has a significant influence on the efficacy of the latter two HGT processes, i.e., on the genes' mobility. The transferability of ARGs is facilitated by the presence of mobility genes in their tight genetic environment. If the genes harbour on plasmids or prophages, the chance of their transfer increases. By probiotics with supposedly mobile ARGs, the likelihood of gene transmission to other bacteria in the intestinal tract increases. In our work, we aimed to gain insight into the mobility of ARGs in probiotics for human consumption using freely available samples sequenced by other research groups or by ourselves. Currently, the few accessible data on probiotic ARG mobility originate from studies with diverse methodologies [6,12-16]. Therefore, we intended to analyse the next-generation sequencing datasets of different probiotics and probiotic isolated bacterial strains with a unified bioinformatics approach.

\section{Materials and Methods}

In this study, we followed the FAO/WHO definition of probiotics, i.e., live microorganisms, which confer a health benefit on the host when administered in adequate amounts [17].

\subsection{Data}

For the study, we selected freely available samples from the sequencing of probiotic products for human consumption or from bacterial strains isolated from such products. The details of analysed samples are listed in Table 1. One probiotic capsule was shotgun sequenced (PRJNA644361) by the authors. All further short read datasets were obtained from NCBI SRA repository.

Table 1. The list of analysed samples obtained from NCBI SRA. In the unified names of the samples the first character corresponds to the type of the sample ( $\mathrm{s}$ and $\mathrm{m}$, isolate and metagenome, respectively), the second tag is a sequence number. Except the signed $\left({ }^{*}\right)$ all samples were paired end sequenced. The last column shows the available information about the biosamples.

\begin{tabular}{|c|c|c|c|}
\hline Sample ID & BioProject & Run & Description \\
\hline \multicolumn{4}{|l|}{ Isolates } \\
\hline s01 & PRJEB14693 & ERR1554589 & Lactiplantibacillus plantarum \\
\hline $\mathrm{s} 02$ & PRJEB14693 & ERR1554590 & Lactiplantibacillus plantarum \\
\hline s03 & PRJEB14693 & ERR1554591 & Lactiplantibacillus plantarum \\
\hline s04 & PRJEB38007 & ERR4421718 & Pseudomonas sp. RGM2144 \\
\hline s05 & PRJNA312743 & SRR3205957 & Limosilactobacillus fermentum \\
\hline s06 & PRJNA347617 & SRR4417252 & Limosilactobacillus fermentum \\
\hline s07 & PRJNA635872 & SRR11966381 & Lactiplantibacillus plantarum \\
\hline s08 & PRJNA639653 & SRR12037315 & Lactobacillus delbrueckii subsp. bulgaricus \\
\hline s09 & PRJNA639653 & SRR12037316 & Lactobacillus delbrueckii subsp. bulgaricus \\
\hline s10 & PRJNA639653 & SRR12037890 & Streptococcus thermophilus \\
\hline s11 & PRJNA649814 & SRR12375795 & Enterococcus faecalis \\
\hline s12 & PRJNA649814 & SRR12375796 & Enterococcus faecalis \\
\hline s13 & PRJNA649814 & SRR12375797 & Enterococcus faecalis \\
\hline s14 & PRJNA650131 & SRR12376423 & Escherichia coli \\
\hline s15 & PRJNA650131 & SRR12376425 & Escherichia coli \\
\hline s16 & PRJNA650131 & SRR12376427 & Escherichia coli \\
\hline s17 & PRJNA650131 & SRR12376429 & Escherichia coli \\
\hline
\end{tabular}


Table 1. Cont

\begin{tabular}{|c|c|c|c|}
\hline Sample ID & BioProject & Run & Description \\
\hline s18 & PRJNA650131 & SRR12376431 & Escherichia coli \\
\hline s19 & PRJNA650131 & SRR12376433 & Escherichia coli \\
\hline s20 & PRJNA639653 & SRR12412204 & Lacticaseibacillus rhamnosus \\
\hline \multicolumn{4}{|l|}{ Microbiota } \\
\hline $\mathrm{m} 01$ & PRJNA474998 & SRR8132838 & probiotic powder (FC13678) \\
\hline $\mathrm{m} 02$ & PRJNA475000 & SRR8138827 & probiotic powder (FC13669) \\
\hline $\mathrm{m} 03$ & PRJNA474989 & SRR8140233 & probiotic powder (FC13655) \\
\hline $\mathrm{m} 04$ & PRJNA474995 & SRR8140386 & probiotic powder (FC13628) \\
\hline $\mathrm{m} 05$ * & PRJNA508569 & SRR8289759 & probiotic product (2) \\
\hline $\mathrm{m} 06$ & PRJNA508569 & SRR8289760 & probiotic product (1) \\
\hline $\mathrm{m} 07$ * & PRJNA508569 & SRR8289761 & probiotic product (4) \\
\hline $\mathrm{m} 08$ * & PRJNA508569 & SRR8289762 & probiotic product (3) \\
\hline $\mathrm{m} 09^{*}$ & PRJNA508569 & SRR8289763 & probiotic product (6) \\
\hline $\mathrm{m} 10$ * & PRJNA508569 & SRR8289764 & probiotic product (5) \\
\hline m11 & PRJNA542229 & SRR9040978 & dietary supplement (PB4) \\
\hline $\mathrm{m} 12$ & PRJNA542229 & SRR9040979 & dietary supplement (PB10) \\
\hline $\mathrm{m} 13$ & PRJNA542229 & SRR9040980 & dietary supplement (PB11) \\
\hline m14 & PRJNA542229 & SRR9040981 & dietary supplement (PB2) \\
\hline m15 & PRJNA542229 & SRR9040982 & dietary supplement (PB14) \\
\hline m16 & PRJNA542229 & SRR9040983 & dietary supplement (PB13) \\
\hline m17 & PRJNA542229 & SRR9040984 & dietary supplement (PB16) \\
\hline $\mathrm{m} 18$ & PRJNA542229 & SRR9040986 & dietary supplement (PB18) \\
\hline m19 & PRJNA542229 & SRR9040987 & dietary supplement (PB17) \\
\hline $\mathrm{m} 20$ & PRJNA542229 & SRR9040988 & dietary supplement (PB8) \\
\hline $\mathrm{m} 21$ & PRJNA542229 & SRR9040989 & dietary supplement (PB19) \\
\hline $\mathrm{m} 22$ & PRJNA542229 & SRR9040990 & dietary supplement (PB12) \\
\hline $\mathrm{m} 23$ & PRJNA542229 & SRR9040991 & dietary supplement (PB9) \\
\hline $\mathrm{m} 24$ & PRJNA542229 & SRR9040992 & dietary supplement (PB6) \\
\hline $\mathrm{m} 25$ & PRJNA542229 & SRR9040993 & dietary supplement (PB5) \\
\hline $\mathrm{m} 26$ & PRJNA542229 & SRR9040994 & dietary supplement (PB7) \\
\hline $\mathrm{m} 27$ & PRJNA644361 & SRR12153424 & probiotic capsule \\
\hline
\end{tabular}

\subsection{DNA Extraction and Metagenomics Library Preparation for PRJNA644361}

Total metagenome DNA of the probiotic capsule sample was extracted using the UltraClean Microbial DNA Isolation kit from MoBio Laboratories. The quality of the isolated total metagenome DNA was checked using an Agilent Tapestation 2200 instrument. The DNA sample was used for in vitro fragment library preparation. In vitro fragment library way prepared using the NEBNext Ultra II DNA Library Prep Kit for Illumina. Paired-end fragment reads were generated on an Illumina NextSeq sequencer using TG NextSeq 500/550 High Output Kit v2 (300 cycles). Primary data analysis (base-calling) was carried out with Bbcl2fastq software (v2.17.1.14, Illumina).

\subsection{Bioinformatic Analysis}

Quality based filtering and trimming of the raw short reads was performed by TrimGalore (v.0.6.6, https:/ / github.com/FelixKrueger/TrimGalore, accessed on 22 Match 2021), setting 20 as a quality threshold. Only reads longer than $50 \mathrm{bp}$ were retained and taxonomically classified using Kraken2 (v2.1.1) [18] and a database created (24 March 2021) from the NCBI RefSeq complete archaeal, bacterial and viral genomes. For this taxon assignment, the -conf idence 0.5 parameter was used to obtain more precise species level hits. The taxon classification data was managed in R [19] using functions of the packages phyloseq [20] and microbiome [21]. The preprocessed reads were assembled to contigs by MEGAHIT (v1.2.9) [22] using default settings. The contigs were also classified taxonomically by Kraken 2 with the same database as above. From the contigs having more than $500 \mathrm{bp}$, all possible open reading frames (ORFs) were gathered by Prodigal (v2.6.3) [23]. 
The protein translated ORFs were aligned to the ARG sequences of the Comprehensive Antibiotic Resistance Database (CARD, v.3.1.1) [24,25] by Resistance Gene Identifier (RGI, v5.1.1) with Diamond [26] The ORFs classified as perfect or strict were further filtered with $90 \%$ identity and $90 \%$ coverage. All nudged hits were excluded. The integrative mobile genetic element (iMGE) content of the ARG harbouring contigs was analysed by MobileElementFinder (v1.0.3) [27]. Following the distance concept of Johansson et al. [27] for each bacterial species, those with a distance threshold defined within iMGEs and ARGs were considered associated. In the MobileElementFinder database (v1.0.2) for Escherichia coli, the longest composite transposon (cTn) was the Tn1681. In the case of this species, its length $(24,488 \mathrm{bp})$ was taken as the cut-off value. For Lactococcus lactis, this threshold was the length of the Tn5721 transposon, 11,256 bp. For Enterococci, the database contained cTn, the Tn6246 (5147 bp) transposon, in E. faecium only. The same threshold was used for E. faecalis contigs. As the database neither contains species-level, nor genus-level cTn data for Bacillus, Bifidobacterium and Streptomyces species, a general cut-off value was chosen for the contigs of these species. This value was declared as the median of the longest cTns per species in the database $(10,098 \mathrm{bp})$. The average nucleotide identity (ANI) was calculated for the region of iMGE and associated ARGs by FastANI (v1.32) [28]. The plasmid origin probability of the contigs was estimated by PlasFlow (v.1.1) [29]. The phage content of the assembled contigs was predicted by VirSorter2 (v2.2.1) [30]. The findings were filtered for dsDNAphages and ssDNAs. All data management procedures, analyses and plottings were performed in R environment (v4.0.4) [19].

\section{Results}

The analysis of the sequencing data from 20 isolates and 27 metagenomic (multimicroorganism) samples (Table 1) is summarised in three sections. Following the presentation of the bacteriome and the identified AGRs (resistome), predictions regarding the mobility potential of ARGs were also summarized based on genetic characteristics that may play a significant role in HGT. If integrated mobile genetic elements (iMGE) are identified in the sequence context of an ARG, its greater mobility can be assumed. The case is the same if the contig harbouring an ARG are derived as plasmid or phage originated. In the mobilome section, we summarise these results.

\subsection{Bacteriome}

By taxon classification, the number of reads aligning to bacterial genomes differed in the various samples. The median bacterial read count of the metagenomic samples was $8.2 \times 10^{6}$ (IQR: $4.4 \times 10^{6}$ ). The median sequencing depth of the isolated strains was 220 (IQR: 94.8). The taxonomic origin of the short reads generated from isolates is shown in Table 1. The relative abundances of genera that achieved more than $1 \%$ of the bacterial hits in any of the metagenomic samples is shown in Figure 1. These dominant genera (with mean prevalence) in descending order were Lactobacillus (40\%), Enterococcus (35\%), Bifidobacterium (34\%), Limosilactobacillus (34\%), Lactococcus (32\%), Lacticaseibacillus (31\%), Bacillus (26\%), Weizmannia (22\%), Ligilactobacillus (19\%), Streptococcus (18\%), Lactiplantibacillus (12\%) and Sphingobacterium (2\%).

\subsection{Resistome}

The median length of the filtered contigs harbouring ARGs constructed by de novo assembly was 102,711 bp (IQR: 105,696). The number of ARGs found on the contigs ranged from 1 to 12. Besides 182 perfect ARG matches, a further 225 hits were classified strict (RGI) and met the criteria of having $90 \%$ coverage and $90 \%$ sequential identity.

ARGs were detected in all metagenomic samples and in few isolates (Figure 2). The majority of isolates (s01, s02, s03, s04, s05, s06, s07, s08, s09, s10, s20) contained no ARG. The highest number of ARGs was found in samples s14-s19, obtained from sequencing six Escherichia coli strains isolated from the same probiotic product. It is important to highlight that we also found the H-NS gene in these samples which is not indicated in the figure, as its 
effect is anti-AMR. The most common ARGs were the rpoB mutants conferring resistance to rifampicin, TEM-116 and tet(W/N/W) genes, detected in 18, 15 and 13 samples, respectively.

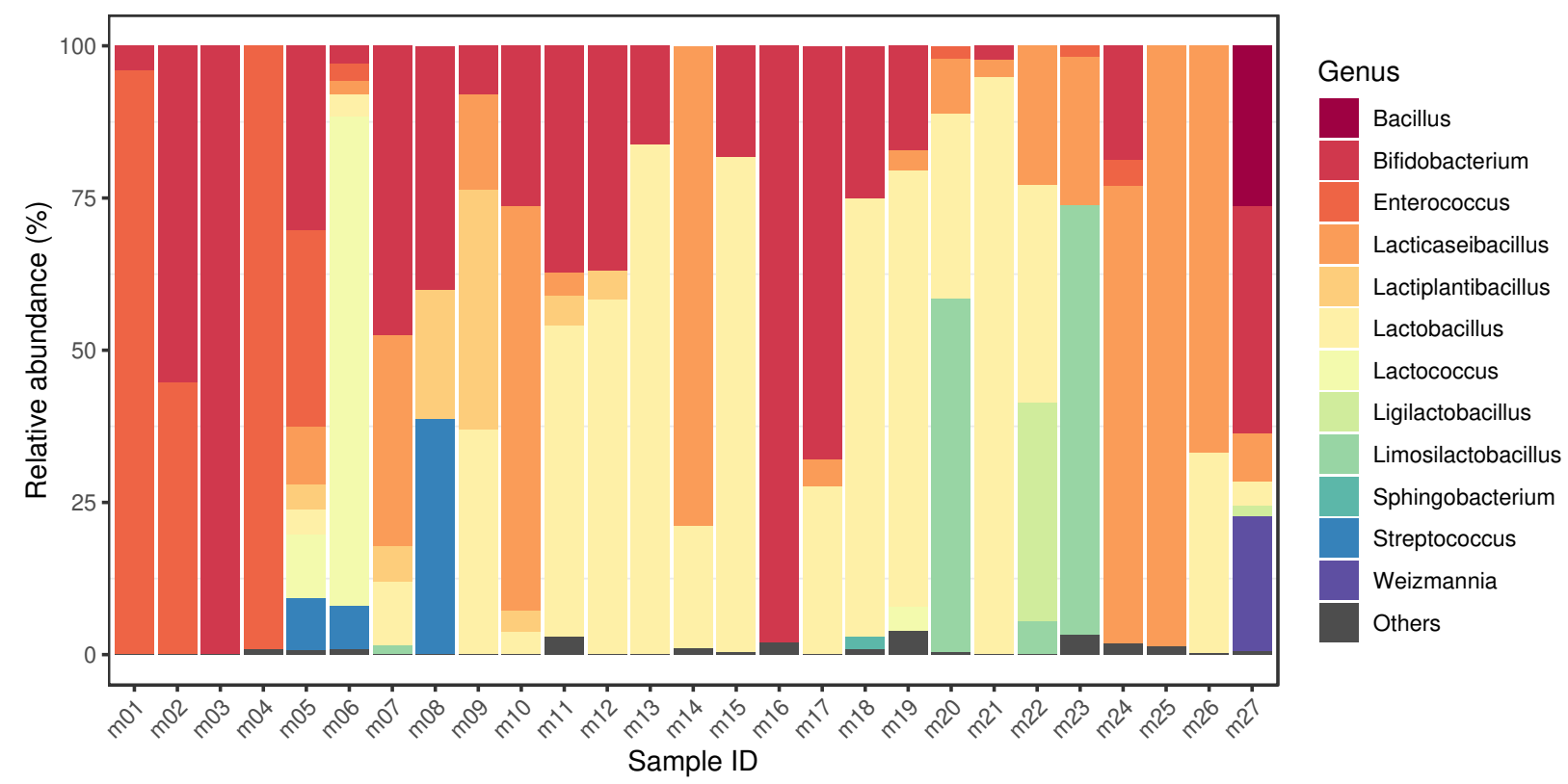

Figure 1. Bacteriome of samples. The relative abundances of genera that achieved more than $1 \%$ of the bacterial hits in any of the metagenomic samples. The dominant genera (with mean prevalence) in descending order were Lactobacillus (40\%), Enterococcus (35\%), Bifidobacterium (34\%), Limosilactobacillus (34\%), Lactococcus (32\%), Lacticaseibacillus (31\%), Bacillus (26\%), Weizmannia (22\%), Ligilactobacillus (19\%), Streptococcus (18\%), Lactiplantibacillus (12\%) and Sphingobacterium (2\%). Sample accession numbers for the Sample IDs are listed in Table 1.

The proportion of resistance mechanisms was calculated based on the ARG diversity. The dominant mechanism of identified ARGs was the antibiotic efflux (58.33\%), antibiotic inactivation $(11.11 \%)$, antibiotic target alteration $(11.11 \%)$, antibiotic target protection $(9.72 \%)$, antibiotic target alteration and antibiotic efflux $(4.17 \%)$, antibiotic efflux and reduced permeability to antibiotic $(1.39 \%)$, antibiotic target alteration and antibiotic efflux and reduced permeability to antibiotic $(1.39 \%)$, antibiotic target alteration and antibiotic target replacement $(1.39 \%)$ and antibiotic target replacement $(1.39 \%)$.

There was no detectable ARG in the studied samples originating from Lacticaseibacillus rhamnosus, Lactiplantibacillus plantarum, Lactobacillus delbrueckii subsp. bulgaricus, Limosilactobacillus fermentum, Pseudomonas sp. RGM2144 or Streptococcus thermophilus species.

The identified ARGs associated with bacteria by species are as follows. Bacillus subtilis: aadK, B. subtilis $m p r F, B$. subtilis pgs $A$ with mutation conferring resistance to daptomycin, $b m r, l m r B, m p h K, v m l R, y k k C, y k k D$. Bifidobacterium animalis: B. adolescentis rpoB mutants conferring resistance to rifampicin, tet $(\mathrm{W} / \mathrm{N} / \mathrm{W})$. B. bifidum: $B$. adolescentis rpoB mutants conferring resistance to rifampicin, $B$. bifidum ileS conferring resistance to mupirocin, tet $(W / N / W)$. B. breve: $B$. adolescentis $r p o B$ mutants conferring resistance to rifampicin, tet $W$. $B$. longum: $B$. adolescentis rpoB mutants conferring resistance to rifampicin, tet $(W / N / W)$. Enterococcus faecalis: dfrE, efr A, efrB, emeA, lsaA, tetM. E. faecium: $A A C\left(6^{\prime}\right)-I i$, eat Av, msrC. Escherichia coli: acrB, acrD, acrE, acrF, acrS, bacA, baeR, baeS, cpxA, CRP, emrA, emrB, emrK, emrR, emrY, eptA, E. coli acrA, E. coli acrR with mutation conferring multidrug antibiotic resistance, E. coli ampC beta-lactamase, E. coli ampC1 beta-lactamase, E. coli ampH beta-lactamase, E. coli emrE, E. coli GlpT with mutation conferring resistance to fosfomycin, E. coli marR mutant conferring antibiotic resistance, E. coli $m d f A$, E. coli soxR with mutation conferring antibiotic resistance, E. coli soxS with mutation conferring antibiotic resistance, $\operatorname{evg} A, \operatorname{evg} S$, gadW, gadX, $k d p E, \operatorname{mar} A, m d t A, m d t B, m d t C, m d t E, m d t F, m d t G, m d t H, m d t M, m d t N, m d t O$, 
mdtP, msbA, PmrF, TEM-116, TolC, ugd, YojI. Lactococcus lactis: lmrD. Streptomyces albulus: $A A C(3)-I V$.

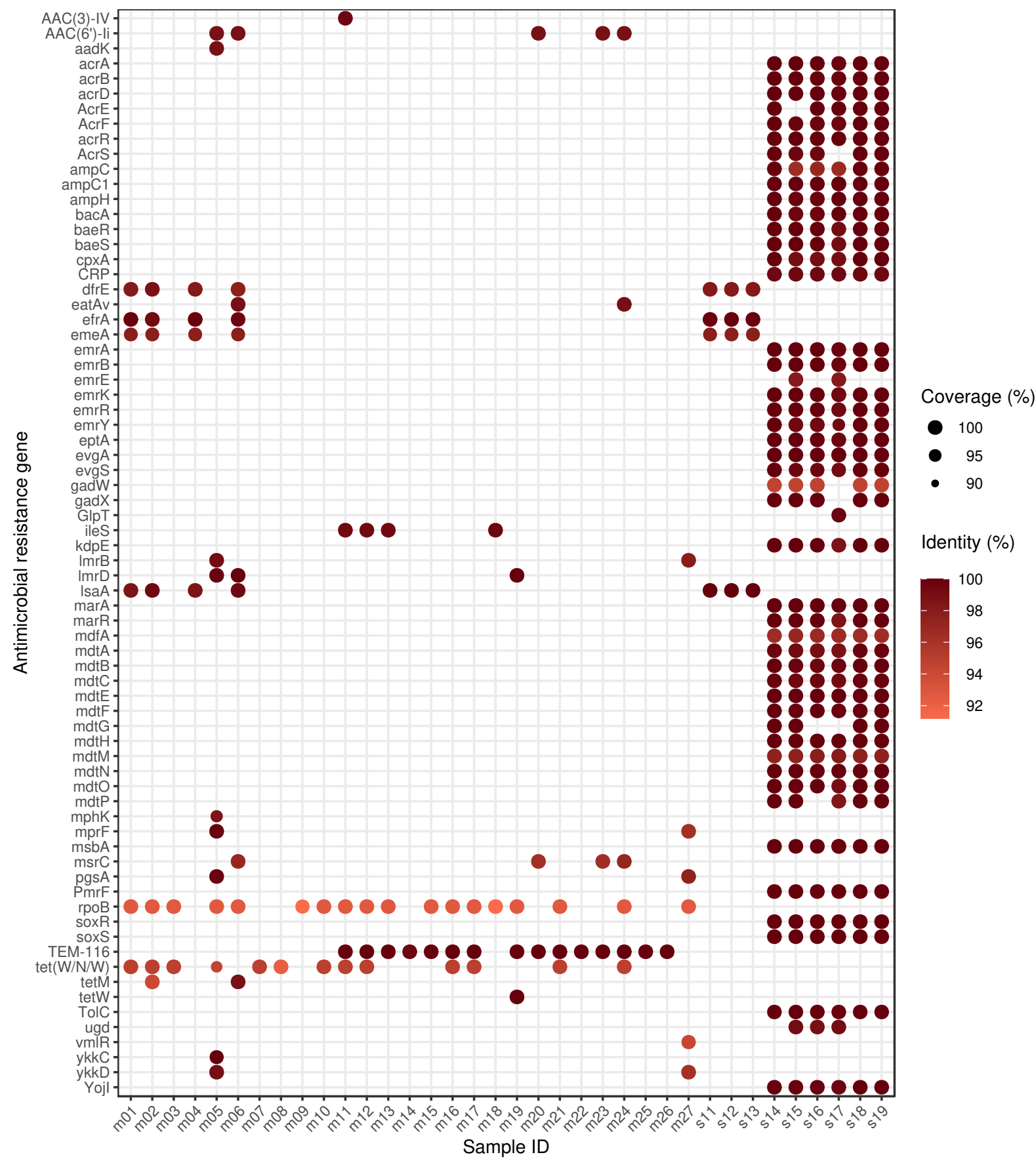

Figure 2. Identifed antimicrobial resistance genes (ARGs) by samples. For each sample-ARG combination, only the best finding is plotted. The size and the colour of the dots correspond to the coverage and the sequence identity of hits on reference genes, respectively. In samples s01-s10 and s20, there was no identifiable ARG. The gene names that are too long have been abbreviated (acrA: Escherichia coli acrA; acrR: E. coli acrR with mutation conferring multidrug antibiotic resistance; ampC: E. coli ampC beta-lactamase; ampC1: E. coli ampC1 beta-lactamase; ampH: E. coli ampH beta-lactamase; emrE: E. coli emrE; GlpT: E. coli GlpT with mutation conferring resistance to fosfomycin; ileS: Bifidobacterium bifidum ileS conferring resistance to mupirocin; marR: E. coli marR mutant conferring antibiotic resistance; $m d f A$ : E. coli mdfA; mprF: Bacillus subtilis mprF; pgsA: $B$. subtilis pgs $A$ with mutation conferring resistance to daptomycin; rpoB: Bifidobacterium adolescentis rpoB mutants conferring resistance to rifampicin; soxR: E. coli soxR with mutation conferring antibiotic resistance; soxS: E. coli soxS with mutation conferring antibiotic resistance). 
The ARGs belonging to the genome of Bacillus subtilis may play a role in the appearance of resistance against aminoglycosides, lincosamides, macrolides, oxazolidinones, peptides, phenicols, pleuromutilins, streptogramins, tetracyclines; Bifidobacterium animalis: rifamycins, tetracyclines; Bifidobacterium bifidum: mupirocins, rifamycins, tetracyclines; Bifidobacterium breve: rifamycins, tetracyclines; Bifidobacterium longum: rifamycins, tetracyclines; Enterococcus faecalis: acridine dye, diaminopyrimidines, fluoroquinolones, lincosamides, macrolides, oxazolidinones, phenicols, pleuromutilins, rifamycins, streptogramins, tetracyclines; Enterococcus faecium: aminoglycosides, lincosamides, macrolides, oxazolidinones, phenicols, pleuromutilins, streptogramins, tetracyclines; Escherichia coli: acridine dye, aminocoumarins, aminoglycosides, benzalkonium chlorides, carbapenems, cephalosporins, cephamycins, fluoroquinolones, fosfomycins, glycylcyclines, lincosamides, macrolides, monobactams, nitroimidazoles, nucleosides, penams, penems, peptides, phenicols, rhodamines, rifamycins, tetracyclines, triclosans; Lactococcus lactis: lincosamides; Streptomyces albulus: aminoglycosides.

\subsection{Mobilome}

The frequencies of iMGEs, phages and plasmids associated with ARGs by bacteria of origin are summarised in Figure 3.

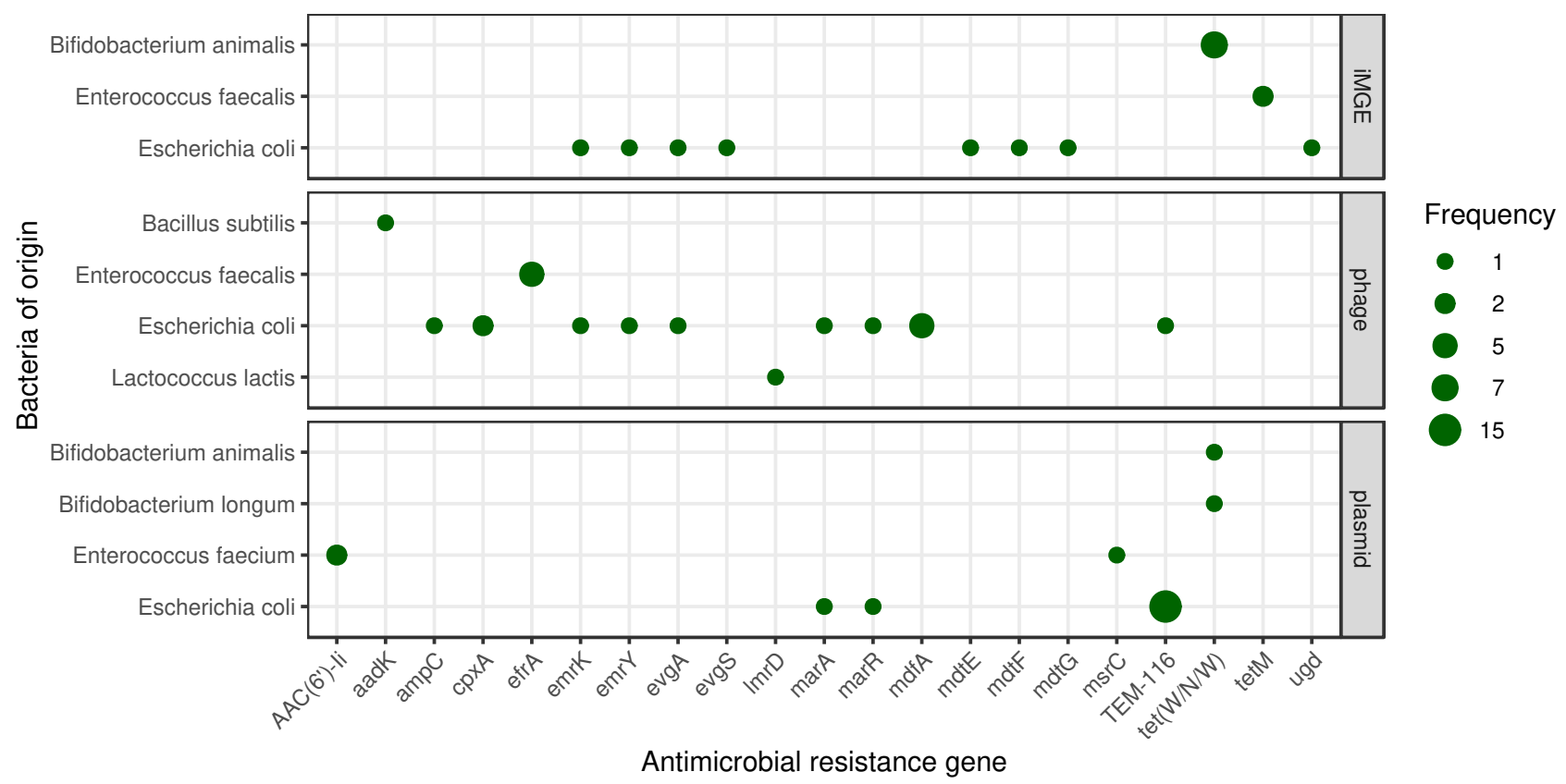

Figure 3. Mobile antimicrobial resistance gene frequency by bacteria of origin. The size of the dots indicates the occurrence frequency of the given gene flanked by iMGE, positioned in plasmid or phage.

\subsection{Coexistence of ARGs and iMGEs}

Based on the distance method proposed by Johansson et al. (2021) [27] iMGE associated ARGs were detected in three species (Bifidobacterium animalis, Enterococcus faecalis and Escherichia coli). In seven metagenomic samples (m01, m02, m03, m07, m16, m17, m24) we found tet $(\mathrm{W} / \mathrm{N} / \mathrm{W})$ associated with ISBian1 insertion sequence on contigs classified as B. animalis originated. In two further samples $(\mathrm{m} 02, \mathrm{~m} 06)$ on $E$. faecalis originated contigs, tet $M$ is linked to the transposon Tn6009. The ARG $m d t G$ in the E. coli sample s14 and the ARG ugd in s15 are associated with IS3 and IS100, respectively. On two different contigs in the sample s17, multiple ARGs were detected with iMGE. One of them has the ISKpn24 associated with $m d t E$ and $m d t F$. The other one has the IS102 linked to emrY, emrK, evgA and $\operatorname{evg} S$ genes. According to the average nucleotide identity (ANI) analysis most of the 
contig region of iMGE and associated ARGs had a high level of conservation (ANI > 97\%). Nevertheless, both contigs classified as E. faecalis originated showed ANIs below 80\%.

\subsection{Plasmids}

In samples m08 and m21, we identified one-one plasmid associated contig with tet $(W / N / W)$ classified as Bifidobacterium longum and Bifidobacterium animalis originated, respectively. In the samples $\mathrm{m} 20$ and $\mathrm{m} 23$ on Enterococcus faecium, classified contigs of plasmids $A A C\left(6^{\prime}\right)$ - $I i$ were detected. Further, E. faecium classified contigs of the sample $\mathrm{m} 23$ contained the gene $\mathrm{msrC}$. In the samples $\mathrm{m} 11, \mathrm{~m} 12, \mathrm{~m} 13, \mathrm{~m} 14, \mathrm{~m} 15, \mathrm{~m} 16, \mathrm{~m} 17, \mathrm{~m} 19$, $\mathrm{m} 20, \mathrm{~m} 21, \mathrm{~m} 22, \mathrm{~m} 23, \mathrm{~m} 24, \mathrm{~m} 25$ and $\mathrm{m} 26$, Escherichia coli originated contigs from plasmids harboured the gene TEM-116. In the E. coli isolate sample s15, one contig of plasmid had the mar $A$ and marR genes.

\subsection{Phages}

By phage prediction, only dsDNAphages were detected. One contig, classified as Bacillus subtilis from the m05 metagenomic sample, contained prophage harbouring gene aadK. One prophage in predicted Enterococcus faecalis originated contig was found in sample $\mathrm{m} 04$ having gene efr $A$. The same content was detected in sample $\mathrm{m} 01$ on contigs classified as E. faecalis. All three E. faecalis isolates (s11, s12, s13) contained contigs harbouring the gene efr $A$ within a prophage. In sample $\mathrm{m} 17$, one $E$. coli classified contig had the gene TEM-116, while a Lactococcus lactis classified one carried the gene $\operatorname{lm} r D$ within a prophage. All the E. coli isolates contained contigs with prophages harbouring ARG. In the sample s17 and s19 the $m d f A$ gene is presented within a prophage. The sample s15 contains contigs harbouring prophage with the gene mar $A, \operatorname{mar} R$. The sample s16 harbours contigs with prophage having genes emrK, emrY, evgA. The gene ampC was found in sample s15, while the gene cpxA in samples s14 and s18 within prophages.

\section{Discussion}

The results presented demonstrate that the bacteria of probiotics may not only carry significant amounts of ARGs, but in numerous cases, those genes may also be mobile, thereby contributing to their spread to other bacteria and having possible consequences on the antibiotic treatment efficacy.

Bacterial genera identified in the metagenomic samples also appear in many probiotic related articles of the current international literature. Various species of Bacilli, Bifidobacteria, Enterococci, Lacticaseibacilli, Lactiplantibacilli, Lactobacilli, Lactococci, Ligilactobacilli, Limosilactobacilli and Streptococci are the core members of commercial probiotic bacterial communities [31-40]. Two identified bacterial genera (Sphingobacterium, Weizmannia) in the various samples are less frequent probiotic components. The possibility of exploiting Sphingobacteria in probiotic foods was previously mentioned based on the characterization of flour and batter samples of sorghum and pearl millet [41]. Members of the genus were detected by the high-throughput sequence analyses of fermented beverages [42]. Probiotic Weizmannia species (e.g., former Bacillus coagulans) have recently been reclassified [43], and have an unquestionable probiotic significance [44]. It is important to note that there may be notable differences in the gene pool between strains of particular species, so the results presented do not mean that all strains of a given species contain the genes identified here.

While at least one ARG was found in each metagenomic sample, less than half of the isolates contained any of them. No ARG was detected in Lacticaseibacillus rhamnosus, Lactiplantibacillus plantarum, Lactobacillus delbrueckii subsp. bulgaricus, Limosilactobacillus fermentum, Pseudomonas sp. RGM2144 or Streptococcus thermophilus. Contigs originating from Bacillus subtilis, Bifidobacterium animalis, Bifidobacterium bifidum, Bifidobacterium breve, Bifidobacterium longum, Enterococcus faecalis, Enterococcus faecium, Escherichia coli, Lactococcus lactis and Streptomyces albulus each contained at least one ARG.

The available literature was screened to evaluate our findings and gain reliable knowledge of the ARGs that could have been attached to bacteria at the species level. All ARGs 
found in Bacillus subtilis (aadK, B. subtilis mprF, B. subtilis pgsA with mutation conferring resistance to daptomycin, $b m r, \operatorname{lm} r B, m p h K, v m l R, y k k C, y k k D$ ) have previously been identified in B. subtilis and many of them were even reported to be specific for this species or the Bacillus genus [45-51]. In the Bifidobacterium genus, ARGs were associated with four species (B. animalis, B. bifidum, B. breve and B. longum). None of the B. animalis, B. bifidum, B. breve and $B$. longum related $B$. adolescentis rpoB mutants conferring resistance to rifampicin and $\operatorname{tet}(W / N / W)$ are specific for the identified species but both genes have previously been described in them [6,52-55]. B. bifidum ileS conferring resistance to mupirocin reported in B. bifidum supposedly cannot be exclusively linked to this species of the genus, but it had been identified in it before [56]. Out of the Enterococcus faecalis deriving genes, $d f r E$ was first identified in E. faecalis [57], but according to a recent study it is not exclusive to this species any more [58]. The genes efr $A$ and efrB have been described in E. faecalis and E. faecium $[59,60]$. Gene eme $A$ has only been identified in E. faecalis so far [59]. Apart from $E$. faecalis, $l s a A$ has been attached to Streptococcus agalactiae, while tet $M$ appears in a broad spectrum of bacterial species [61-65]. All three ARGs $\left(A A C\left(6^{\prime}\right)-I i\right.$, eat $\left.A v, m s r C\right)$ associated with $E$. faecium have been previously published as appearing in this species, and the first two are even specific for it [66-69]. All ARGs originating from Escherichia coli ( $a c r B, a c r D, a c r E, a c r F, a c r S, b a c A, b a e R, b a e S, c p x A, C R P$, emr A, emrB, emrK, emrR, emrY, ept $A$, E. coli acr $A, E$. coli acrR with mutation conferring multidrug antibiotic resistance, $E$. coli ampC beta-lactamase, E. coli ampC1 beta-lactamase, E. coli ampH beta-lactamase, E. coli emrE, E. coli GlpT with mutation conferring resistance to fosfomycin, E. coli marR mutant conferring antibiotic resistance, E. coli $m d f A$, E. coli soxR with mutation conferring antibiotic resistance, E. coli soxS with mutation conferring antibiotic resistance, $\operatorname{evg} A, \operatorname{evg} S, \operatorname{gad} W$, $\operatorname{gadX}, k d p E, \operatorname{mar} A, m d t A, m d t B, m d t C, m d t E, m d t F, m d t G, m d t H, m d t M, m d t N, m d t O, m d t P$, $m s b A, P m r F, T E M-116$, TolC, ugd, YojI) have previously been described in this species and many of them are even specific to it, according to the Comprehensive Antibiotic Resistance Database (CARD) [24,25]. Gene $l m r D$, the only ARG deriving from Lactococcus lactis has been identified in this species along with some others [70,71]. Even though $A A C(3)-I V$ has been identified in several studies [72,73], according to our knowledge this is the first time it has been detected in Streptomyces albulus.

Gene TEM-116, which is often referred to as a clinically significant extended-spectrum beta-lactamase (ESBLs), was the most frequently identified finding in our study. ESBLs are most commonly defined as the members of a ubiquitous enzyme family that is capable of conferring resistance to penicillins, first-, second- and third-generation cephalosporins and aztreonam, and of being impeded by beta-lactamase inhibitors such as clavulanic acid [74]. The 400 TEM variants that have been identified so far, can be disclosed in two clusters with one deriving from TEM-1 (the first TEM protein to be described) and one linked to TEM-116 as a progenitor [75]. In line with our findings, gene TEM-116 is reported to be present worldwide harbouring in the conjugative plasmids of a wide range of Gramnegative bacteria. Despite its wide geographical dissemination, establishment on multiple plasmids and centrality in the TEM family network indicating it is a naturally occurring enzyme with microbiologically proven ESBL characteristics [76,77], some concerns have arisen about its designation, after the gene was found in non-ESBL producing Klebsiella pneumoniae strains [78]. Moreover, commercial Taq polymerases used in PCRs may be contaminated with $b l a_{T E M-116}$ DNA which could lead to the erroneous identification of the gene in samples that do not actually contain it $[79,80]$. In our study, each sample in which this gene was detected originated from the same bioproject (PRJNA542229). As the samples come from different dietary supplements, one may interpret that this finding is an artefact or contamination as a consequence of some sample preparation steps. Nevertheless, as more detailed information on sample preparation is not available, this issue cannot be resolved.

As seen above, and as described in other publications [81], there is still a great deal of variation in details which need to be clarified by the interpretation of ARGs. Nevertheless, the suspicion that the identified ARGs may undermine the efficacy of several antibiotic 
classes, including acridine dye, aminocoumarins, aminoglycosides, benzalkonium chloride, carbapenems, cephalosporins, cephamycins, diaminopyrimidines, fluoroquinolones, fosfomycins, glycylcyclines, lincosamides, macrolides, monobactams, mupirocins, nitroimidazoles, nucleosides, oxazolidinones, penams, penems, peptides, phenicols, pleuromutilins, rhodamines, rifamycins, streptogramins, tetracyclines and triclosans raises some clinical considerations. According to the latest CDC report on antimicrobial use in the U.S., amoxicillin (penam), azithromycin (aminoglycoside), amoxicillin and clavunalic acid (penam, increased activity), cephalexin (cephalosporin) and doxycycline (tetracycline) are the most commonly administered compounds [82]. Moreover, based on the latest WHO report on global antimicrobial use, amoxicillin (penam), ciprofloxacin (fluoroquinolon), sulphametoxazole and trimethoprim are the most commonly prescribed oral drugs and ceftriaxone (cephalosporin), gentamicin (aminogylcoside) and benzylpenicillin (penam) are the most commonly used parenteral compounds in 4 surveyed countries of the African region. In six countries of the region of the Americas, amoxicillin (penam), cefalexin (cephalosporin) and doxycycline (tetracycline) are the antibiotics with the highest oral consumption rates and ceftriaxone (cephalosporin), oxacillin (penam) and gentamicin (aminogylcoside) are the ones with the highest parenteral use. In the European region, reports were made of 46 countries. Among orally administered antibiotics, amoxicillin (penam), amoxicillin and beta-lactamase inhibitors (penam, increased activity) and doxycycline (tetracycline) are the top 3 compounds, while ceftriaxone (cephalosporin), gentamicin (amynoglycoside), and cefazoline (cephalosporin) are the most common parenteral ones. Amoxicillin (penam), azithromycin (macrolide) and amoxicillin and beta-lactamase inhibitors (penam, increased activity) are the most commonly consumed oral antibiotics and ceftriaxone (cephalosporin), benzathine benzylpenicillin (penam) and procaine benzylpenicillin (penam) are the top 3 parenterally administered agents in the Eastern Mediterranean region. In the six surveyed countries of the Western Pacific region amoxicillin (penam), doxycycline (tetracycline) and amoxicillin and beta-lactamase inhibitors (penam, increased activity) are the most commonly prescribed oral antibiotics, while cefazolin (cephalosporin), ceftriaxone (cephalosporin) and cefuroxime (cephalosporin) are the most frequently used parenteral compounds [83]. Many of the most highly prioritized antibiotics could be affected by the presence of the detected ARGs. Meanwhile, out of the 15 antibiotic groups mentioned in the latest WHO report on critically important antimicrobials (CIA) for human medicine, nine (aminoglycosides, carbapenems and other penems, cephalosporins, glycylcyclines, macrolides, monobactams, oxazolidinones, penicillins of various cathegories, quinolones) could possibly be affected by the ARGs identified in the various samples [83].

It is important to underline that all the six E. coli isolates contained the gene H-NS, which plays a crucial role in the global gene regulation of various bacteria, including this species. The expression of a wide variety of genes is repressed by $\mathrm{H}-\mathrm{NS}$, and its deletion increases AMR and decreases drug accumulation. Even though this gene is stored in CARD [24,25], its functional effect is adverse to that produced by ARGs [84].

If ARGs are transmitted from probiotic bacteria to pathogenic bacteria within the consumer's body, they may reduce the effectiveness of antibiotic therapy on the diseases participating pathogenic bacteria cause. The execution of gene transfer processes is more likely among bacteria that are in close physical proximity to each other and if the ARGs are associated to a mobile genetic environment. According to our results a considerable number of ARGs, such as those which are iMGEs-linked or have resided in plasmids or prophages.

The co-occurence of $\operatorname{tet}(\mathrm{W} / \mathrm{N} / \mathrm{W})$ and ISBian1 is in line with the findings of Rozman et al. [6], according to which all genomes of B. animalis (subspecies lactis or animalis) $(n=42)$ available in 2019 contained this gene. Moreover, by the investigation of the mobility characteristics of $t e t W$, out of the transposases belonging to the family of the insertion sequences, ISBian1 seemed to be subspecies dependent in B. animalis subsp. lactis and flanking tet $W$ in the majority of the strains [6]. Our results of tet $M$ linking to the transposon Tn6009 in E. faecalis is consistent with finding of Zangue et al. in South-African fecal samples [85]. 
In two samples, contigs harbouring tet $(\mathrm{W} / \mathrm{N} / \mathrm{W})$ originating from Bifidobacterium longum and Bifidobacterium animalis were predicted to belong to plasmids. Several studies reported a wide prevalence of the tet $W$ gene in Bifidobacteria $[6,12,86,87]$. While the co-occurrence of tet $W$ and its flanking transposase is a common genetic feature of $B$. animalis, previous reports lack the identification of plasmids in $B$. animalis, even though the gene was associated with plasmids in other bacterial species [88]. Despite $A A C\left(6^{\prime}\right)$-Ii deriving from $E$. faecium being located in the chromosome in previous studies and it being defined as a chromosome-borne ARG on CARD [24,25,89], our research indicates it may take place in a plasmid. An E. faecium-associated contig contained gene msrC. According to the available literature, $m s r C$ is a chromosomal-encoded gene that is mentioned as an intrinsic property of E. faecium strains [24,25,90]. While the expected bacterial species of origin was confirmed, our finding raises the likelihood of the gene being connected to a plasmid as well. In 15 samples, E. coli-originated contigs harboured the gene TEM-116. Plasmid origin is a common feature of ESBL genes such as TEM-116 according to several publications and is often referred to as a feature to facilitate their quick spread [91-93]. In the E. coli isolate sample s15, one contig had the mar $A$ and $\operatorname{mar} R$ genes. These widespread multiple antibiotic resistance genes had been identified on plasmids before [94]. The gene efr $A$ harbouring in contigs with a prediction of phage origins were identified in all publicly available E. faecalis genome sequences by Panthee and colleges too, along with a large set of phages in the genomes [95].

As our results derive from in silico data analysis, it is only possible to describe the features that prove and facilitate presence and mobility of the genes. Whether or not the identified genes operate in the bacterial strains of a given probiotic cannot be determined. In order to clarify this, additional functional, e.g., gene expression studies, should be performed.

An important aspect to take into consideration by the interpretation of the ARG occurrence in probiotics is that constituent strains can often naturally be, or rendered multiresistant, so that they can be co-administered with oral antibiotics and reduce gastrointestinal side effects [96,97]. In our study we could not distinguish whether the examined samples contained the ARGs for this purpose. Moreover, as ARGs were found in the vast majority of the samples tested, not a negligible proportion of them, it is possible that the presence of ARGs in bacteria may also play a role in their probiotic effect. ARGs play a role in defence against antibiotics and may provide general fitness against specific toxic effects for bacteria $[98,99]$. One may make an analogy with earlier practice. In livestock farming, antibiotics have been widely used as feed supplements for yield enhancement on a purely empirical basis. By this practice, antibiotics have put pressure on the gut bacteria and selected for resistant strains. As a result, animal feed efficiency and production indicators have improved. When probiotics are consumed, the expectation is that the "good" microorganisms, bacteria will colonise the gut. In numerous animal husbandry areas (e.g., broiler chicken production), the producers try to achieve this by continuous probiotic feeding. If these probiotics also contain bacterial strains harbouring ARGs, they achieve very similar results as before with the selective effect of antibiotic utilisation. If it is true that certain ARGs are essential for the efficacy of probiotic bacteria, then the selection of strains should be carried out with consideration of the human health consequences. That is, bacterial strains that contain ARGs having no significant influence on human antimicrobial therapy efficiency should be used. However, based on our results, it can also be suggested that bacteria that do not contain ARGs at all can be used as probiotic components. To have a more detailed insight into this topic, several further studies would be needed. For instance, they could also focus on reducing the mobility of genes whose presence may be necessary for the probiotic nature of particular bacteria. Based on the results, we consider it essential to monitor the ARG content of probiotic preparations and their mobility characteristics in the fight against antimicrobial resistance. 
Author Contributions: N.S. takes responsibility for the integrity of the data and the accuracy of the data analysis. A.G.T., I.C., N.S. and S.S. conceived the concept of the study. G.M., N.S. and S.S. performed sample collection and procedures. Á.B., A.G.T. and N.S. participated in the bioinformatic analysis. Á.B., A.G.T., G.M., I.C., M.F.J. and N.S. participated in the drafting of the manuscript. Á.B., A.G.T., G.M., I.C., M.F.J., N.S. and S.S. carried out the critical revision of the manuscript for important intellectual content. All authors have read and agreed to the published version of the manuscript.

Funding: The research was supported by the TKP 2020-4.1.1.-TKP2020 of ITM Hungary, within the Digital Biomarker thematic programme of the Semmelweis University. It has also received funding from the European Union's Horizon 2020 research and innovation program under Grant Agreement No. 874735 (VEO). GM received support from the Hungarian Academy of Sciences through the Lendület-Programme (LP2020-5/2020).

Institutional Review Board Statement: Not applicable.

Informed Consent Statement: Not applicable.

Data Availability Statement: The short read data of sample data are publicly available and can be accessed through the PRJEB14693, PRJEB38007, PRJNA312743, PRJNA347617, PRJNA474989, PRJNA474995, PRJNA474998, PRJNA475000, PRJNA508569 [100], PRJNA542229, PRJNA577063, PRJNA635872, PRJNA639653, PRJNA644361, PRJNA649814, PRJNA650131 from the NCBI Sequence Read Archive (SRA).

Acknowledgments: The authors would like to thank the providers of BioProjects (PRJEB14693, PRJEB38007, PRJNA312743, PRJNA347617, PRJNA474989, PRJNA474995, PRJNA474998, PRJNA475000, PRJNA508569, PRJNA542229, PRJNA577063, PRJNA635872, PRJNA639653, PRJNA649814, PRJNA650131).

Conflicts of Interest: The authors declare no conflict of interest.

\section{References}

1. Sanders, M.; Merenstein, D.; Merrifield, C.; Hutkins, R. Probiotics for human use. Nutr. Bull. 2018, 43, 212-225. [CrossRef]

2. Zmora, N.; Zilberman-Schapira, G.; Suez, J.; Mor, U.; Dori-Bachash, M.; Bashiardes, S.; Kotler, E.; Zur, M.; Regev-Lehavi, D.; Brik, R.B.Z.; et al. Personalized gut mucosal colonization resistance to empiric probiotics is associated with unique host and microbiome features. Cell 2018, 174, 1388-1405. [CrossRef]

3. Gopalakrishnan, V.; Spencer, C.N.; Nezi, L.; Reuben, A.; Andrews, M.; Karpinets, T.; Prieto, P.; Vicente, D.; Hoffman, K.; Wei, S.; et al. Gut microbiome modulates response to anti-PD-1 immunotherapy in melanoma patients. Science 2018, 359, 97-103. [CrossRef]

4. Zheng, M.; Zhang, R.; Tian, X.; Zhou, X.; Pan, X.; Wong, A. Assessing the risk of probiotic dietary supplements in the context of antibiotic resistance. Front. Microbiol. 2017, 8, 908. [CrossRef]

5. Berreta, A.; Baumgardner, R.M.; Kopper, J.J. Evaluation of commercial veterinary probiotics containing enterococci for transferrable vancomycin resistance genes. BMC Res. Notes 2020, 13, 1-6. [CrossRef] [PubMed]

6. Rozman, V.; Lorbeg, P.M.; Accetto, T.; Matijašić, B.B. Characterization of antimicrobial resistance in lactobacilli and bifidobacteria used as probiotics or starter cultures based on integration of phenotypic and in silico data. Int. J. Food Microbiol. 2020, 314, 108388. [CrossRef] [PubMed]

7. Selvin, J.; Maity, D.; Sajayan, A.; Kiran, G.S. Revealing antibiotic resistance in therapeutic and dietary probiotic supplements. J. Glob. Antimicrob. Resist. 2020, 22, 202-205. [CrossRef] [PubMed]

8. EFSA Panel on Additives and Products or Substances used in Animal Feed (FEEDAP); Rychen, G.; Aquilina, G.; Azimonti, G.; Bampidis, V.; Bastos, M.d.L.; Bories, G.; Chesson, A.; Cocconcelli, P.S.; Flachowsky, G. Guidance on the characterisation of microorganisms used as feed additives or as production organisms. EFSA J. 2018, 16, e05206.

9. European Food Safety Authority. EFSA statement on the requirements for whole genome sequence analysis of microorganisms intentionally used in the food chain. EFSA J. 2021, 19, e06506.

10. Cabezón, E.; Ripoll-Rozada, J.; Peña, A.; De La Cruz, F.; Arechaga, I. Towards an integrated model of bacterial conjugation. FEMS Microbiol. Rev. 2015, 39, 81-95. [CrossRef] [PubMed]

11. Goh, S. Phage transduction. In Clostridium Difficile; Humana Press: New York, NY, USA, 2016; pp. 177-185.

12. Aires, J.; Doucet-Populaire, F.; Butel, M. Tetracycline resistance mediated by tet $(\mathrm{W})$, tet $(\mathrm{M})$, and tet $(\mathrm{O})$ genes of Bifidobacterium isolates from humans. Appl. Environ. Microbiol. 2007, 73, 2751-2754. [CrossRef]

13. Ammor, M.S.; Flórez, A.B.; Van Hoek, A.H.; Clara, G.; Aarts, H.J.; Margolles, A.; Mayo, B. Molecular characterization of intrinsic and acquired antibiotic resistance in lactic acid bacteria and bifidobacteria. J. Mol. Microbiol. Biotechnol. 2008, 14, 6-15. [CrossRef]

14. Bennedsen, M.; Stuer-Lauridsen, B.; Danielsen, M.; Johansen, E. Screening for antimicrobial resistance genes and virulence factors via genome sequencing. Appl. Environ. Microbiol. 2011, 77, 2785-2787. [CrossRef] [PubMed] 
15. Gueimonde, M.; Sánchez, B.; de Los Reyes-Gavilán, C.G.; Margolles, A. Antibiotic resistance in probiotic bacteria. Front. Microbiol. 2013, 4, 202. [CrossRef]

16. Mancino, W.; Lugli, G.A.; van Sinderen, D.; Ventura, M.; Turroni, F. Mobilome and resistome reconstruction from genomes belonging to members of the Bifidobacterium genus. Microorganisms 2019, 7, 638. [CrossRef] [PubMed]

17. FAO/WHO. Health and Nutritional Properties of Probiotics in Food Including Powder Milk with Live Lactic Acid Bacteria; Food and Agriculture Organization of the United Nations and World Health Organization Expert Consultation Report; FAO: Cordoba, Argentina, 2001.

18. Wood, D.E.; Lu, J.; Langmead, B. Improved metagenomic analysis with Kraken 2. Genome Biol. 2019, 20, 257. [CrossRef]

19. R Core Team. R: A Language and Environment for Statistical Computing; R Foundation for Statistical Computing: Vienna, Austria, 2021.

20. McMurdie, P.J.; Holmes, S. Phyloseq: An R Package for Reproducible Interactive Analysis and Graphics of Microbiome Census Data. PLoS ONE 2013, 8, e61217.

21. Lahti, L.; Shetty, S. Microbiome R package, 2012-2019. Available online: http:/ / microbiome.github.io (accessed on 22 March 2021).

22. Li, D.; Liu, C.M.; Luo, R.; Sadakane, K.; Lam, T.W. MEGAHIT: An ultra-fast single-node solution for large and complex metagenomics assembly via succinct de Bruijn graph. Bioinformatics 2015, 31, 1674-1676. [CrossRef] [PubMed]

23. Hyatt, D.; Chen, G.L.; LoCascio, P.F.; Land, M.L.; Larimer, F.W.; Hauser, L.J. Prodigal: Prokaryotic gene recognition and translation initiation site identification. BMC Bioinform. 2010, 11, 119. [CrossRef]

24. McArthur, A.G.; Waglechner, N.; Nizam, F.; Yan, A.; Azad, M.A.; Baylay, A.J.; Bhullar, K.; Canova, M.J.; De Pascale, G.; Ejim, L.; et al. The comprehensive antibiotic resistance database. Antimicrob. Agents Chemother. 2013, 57, 3348-3357. [CrossRef]

25. Jia, B.; Raphenya, A.R.; Alcock, B.; Waglechner, N.; Guo, P.; Tsang, K.K.; Lago, B.A.; Dave, B.M.; Pereira, S.; Sharma, A.N.; et al. CARD 2017: Expansion and model-centric curation of the comprehensive antibiotic resistance database. Nucleic Acids Res. 2017, 45, D566-D573. [CrossRef]

26. Buchfink, B.; Xie, C.; Huson, D.H. Fast and sensitive protein alignment using DIAMOND. Nat. Methods 2015, 12, 59-60. [CrossRef]

27. Johansson, M.H.; Bortolaia, V.; Tansirichaiya, S.; Aarestrup, F.M.; Roberts, A.P.; Petersen, T.N. Detection of mobile genetic elements associated with antibiotic resistance in Salmonella enterica using a newly developed web tool: MobileElementFinder. J. Antimicrob. Chemother. 2021, 76, 101-109. [CrossRef]

28. Jain, C.; Rodriguez-R, L.M.; Phillippy, A.M.; Konstantinidis, K.T.; Aluru, S. High throughput ANI analysis of 90K prokaryotic genomes reveals clear species boundaries. Nat. Commun. 2018, 9, 1-8. [CrossRef]

29. Krawczyk, P.S.; Lipinski, L.; Dziembowski, A. PlasFlow: Predicting plasmid sequences in metagenomic data using genome signatures. Nucleic Acids Res. 2018, 46, e35. [CrossRef] [PubMed]

30. Guo, J.; Bolduc, B.; Zayed, A.A.; Varsani, A.; Dominguez-Huerta, G.; Delmont, T.O.; Pratama, A.A.; Gazitúa, M.C.; Vik, D.; Sullivan, M.B.; et al. VirSorter2: A multi-classifier, expert-guided approach to detect diverse DNA and RNA viruses. Microbiome 2021, 9, 1-13. [CrossRef]

31. Duc, L.H.; Hong, H.A.; Barbosa, T.M.; Henriques, A.O.; Cutting, S.M. Characterization of Bacillus probiotics available for human use. Appl. Environ. Microbiol. 2004, 70, 2161-2171. [CrossRef]

32. Adel, M.; El-Sayed, A.F.M.; Yeganeh, S.; Dadar, M.; Giri, S.S. Effect of potential probiotic Lactococcus lactis subsp. lactis on growth performance, intestinal microbiota, digestive enzyme activities, and disease resistance of Litopenaeus vannamei. Probiotics Antimicrob. Proteins 2017, 9, 150-156. [CrossRef]

33. Baccouri, O.; Boukerb, A.M.; Farhat, L.B.; Zébré, A.; Zimmermann, K.; Domann, E.; Cambronel, M.; Barreau, M.; Maillot, O.; Rincé, I.; et al. Probiotic potential and safety evaluation of Enterococcus faecalis OB14 and OB15, isolated from traditional tunisian testouri cheese and rigouta, using physiological and genomic analysis. Front. Microbiol. 2019, 10, 881. [CrossRef] [PubMed]

34. Poorni, S.; Srinivasan, M.R.; Nivedhitha, M.S. Probiotic Streptococcus strains in caries prevention: A systematic review. J. Conserv. Dent. JCD 2019, 22, 123. [CrossRef] [PubMed]

35. Bozkurt, H.S.; Quigley, E.M. The probiotic Bifidobacterium in the management of Coronavirus: A theoretical basis. Int. J. Immunopathol. Pharmacol. 2020, 34, 2058738420961304. [CrossRef]

36. Drago, L.; Meroni, G.; Chiaretti, A.; Laforgia, N.; Cucchiara, S.; Baldassarre, M.E. Effect of Limosilactobacillus reuteri LRE02Lacticaseibacillus rhamnosus LR04 Combination on Antibiotic-Associated Diarrhea in a Pediatric Population: A National Survey. J. Clin. Med. 2020, 9, 3080. [CrossRef]

37. Minj, J.; Chandra, P.; Paul, C.; Sharma, R.K. Bio-functional properties of probiotic Lactobacillus: Current applications and research perspectives. Crit. Rev. Food Sci. Nutr. 2020, 61, 2207-2264. [CrossRef] [PubMed]

38. Dec, M.; Stępień-Pyśniak, D.; Puchalski, A.; Hauschild, T.; Pietras-Ożga, D.; Ignaciuk, S.; Urban-Chmiel, R. Biodiversity of Ligilactobacillus salivarius Strains from Poultry and Domestic Pigeons. Animals 2021, 11, 972. [CrossRef]

39. Garcia-Gonzalez, N.; Battista, N.; Prete, R.; Corsetti, A. Health-Promoting Role of Lactiplantibacillus plantarum Isolated from Fermented Foods. Microorganisms 2021, 9, 349. [CrossRef] [PubMed]

40. Hussain, N.; Li, R.; Takala, T.M.; Tariq, M.; Zaidi, A.H.; Saris, P.E. Generation of Lactose-and Protease-Positive Probiotic Lacticaseibacillus rhamnosus GG by Conjugation with Lactococcus lactis NCDO 712. Appl. Environ. Microbiol. 2021, 87, e02957-20. [CrossRef] [PubMed]

41. Kunchala, R.; Banerjee, R.; Mazumdar, S.D.; Durgalla, P.; Srinivas, V.; Gopalakrishnan, S. Characterization of potential probiotic bacteria isolated from sorghum and pearl millet of the semi-arid tropics. Afr. J. Biotechnol. 2016, 15, 613-621. 
42. Ezekiel, C.N.; Ayeni, K.I.; Ezeokoli, O.T.; Sulyok, M.; van Wyk, D.A.; Oyedele, O.A.; Akinyemi, O.M.; Chibuzor-Onyema, I.E.; Adeleke, R.A.; Nwangburuka, C.C.; et al. High-throughput sequence analyses of bacterial communities and multi-mycotoxin profiling during processing of different formulations of Kunu, a traditional fermented beverage. Front. Microbiol. 2019,9 , 3282. [CrossRef] [PubMed]

43. Gupta, R.S.; Patel, S.; Saini, N.; Chen, S. Robust demarcation of 17 distinct Bacillus species clades, proposed as novel Bacillaceae genera, by phylogenomics and comparative genomic analyses: Description of Robertmurraya kyonggiensis sp. nov. and proposal for an emended genus Bacillus limiting it only to the members of the Subtilis and Cereus clades of species. Int. J. Syst. Evol. Microbiol. 2020, 70, 5753-5798. [PubMed]

44. Cao, J.; Yu, Z.; Liu, W.; Zhao, J.; Zhang, H.; Zhai, Q.; Chen, W. Probiotic characteristics of Bacillus coagulans and associated implications for human health and diseases. J. Funct. Foods 2020, 64, 103643. [CrossRef]

45. Keiichi, O.; Takaaki, T.; Norihisa, N.; Megumi, K. Nucleotide sequence of the chromosomal gene coding for the aminoglycoside 6-adenylyltransferase from Bacillus subtilis Marburg 168. Gene 1989, 78, 377-378. [CrossRef]

46. Klyachko, K.A.; Schuldiner, S.; Neyfakh, A.A. Mutations affecting substrate specificity of the Bacillus subtilis multidrug transporter Bmr. J. Bacteriol. 1997, 179, 2189-2193. [CrossRef]

47. Jack, D.L.; Storms, M.L.; Tchieu, J.H.; Paulsen, I.T.; Saier, M.H. A broad-specificity multidrug efflux pump requiring a pair of homologous SMR-type proteins. J. Bacteriol. 2000, 182, 2311-2313. [CrossRef] [PubMed]

48. Yoshida, K.I.; Ohki, Y.H.; Murata, M.; Kinehara, M.; Matsuoka, H.; Satomura, T.; Ohki, R.; Kumano, M.; Yamane, K.; Fujita, Y. Bacillus subtilis LmrA is a repressor of the $1 \mathrm{mrAB}$ and yxaGH operons: Identification of its binding site and functional analysis of lmrB and yxaGH. J. Bacteriol. 2004, 186, 5640-5648. [CrossRef] [PubMed]

49. Hachmann, A.B.; Sevim, E.; Gaballa, A.; Popham, D.L.; Antelmann, H.; Helmann, J.D. Reduction in membrane phosphatidylglycerol content leads to daptomycin resistance in Bacillus subtilis. Antimicrob. Agents Chemother. 2011, 55, 4326-4337. [CrossRef] [PubMed]

50. Crowe-McAuliffe, C.; Graf, M.; Huter, P.; Takada, H.; Abdelshahid, M.; Nováček, J.; Murina, V.; Atkinson, G.C.; Hauryliuk, V.; Wilson, D.N. Structural basis for antibiotic resistance mediated by the Bacillus subtilis ABCF ATPase VmlR. Proc. Natl. Acad. Sci. USA 2018, 115, 8978-8983. [CrossRef]

51. Pawlowski, A.C.; Stogios, P.J.; Koteva, K.; Skarina, T.; Evdokimova, E.; Savchenko, A.; Wright, G.D. The evolution of substrate discrimination in macrolide antibiotic resistance enzymes. Nat. Commun. 2018, 9, 1-12. [CrossRef]

52. Kim, B.J.; Kim, H.Y.; Yun, Y.J.; Kim, B.J.; Kook, Y.H. Differentiation of Bifidobacterium species using partial RNA polymerase $\beta$-subunit (rpoB) gene sequences. Int. J. Syst. Evol. Microbiol. 2010, 60, 2697-2704. [CrossRef]

53. Lokesh, D.; Parkesh, R. Bifidobacterium adolescentis is intrinsically resistant to antitubercular drugs. Sci. Rep. 2018, 8, 1-15. [CrossRef]

54. Polit, A.; Yang, H.; Amund, D. Investigating the transmissibility of tet (W) in bifidobacteria exposed to acid and bile stress. Biosci. Microbiota Food Health 2018, 37, 39-43. [CrossRef]

55. Tóth, A.G.; Csabai, I.; Maróti, G.; Jerzsele, Á.; Dubecz, A.; Patai, Á.V.; Judge, M.F.; Nagy, S.Á.; Makrai, L.; Bányai, K.; et al. A glimpse of antimicrobial resistance gene diversity in kefir and yoghurt. Sci. Rep. 2020, 10, 1-12. [CrossRef] [PubMed]

56. Serafini, F.; Bottacini, F.; Viappiani, A.; Baruffini, E.; Turroni, F.; Foroni, E.; Lodi, T.; van Sinderen, D.; Ventura, M. Insights into physiological and genetic mupirocin susceptibility in bifidobacteria. Appl. Environ. Microbiol. 2011, 77, 3141-3146. [CrossRef]

57. Coque, T.M.; Singh, K.V.; Weinstock, G.M.; Murray, B.E. Characterization of Dihydrofolate Reductase Genes from TrimethoprimSusceptible and Trimethoprim-Resistant Strains ofEnterococcus faecalis. Antimicrob. Agents Chemother. 1999, 43, 141-147. [CrossRef]

58. Gómez-Sanz, E.; Haro-Moreno, J.M.; Jensen, S.O.; Roda-Garcia, J.J.; Lopez-Perez, M. Staphylococcus sciuri C2865 from a distinct subspecies cluster as reservoir of the novel transferable trimethoprim resistance gene, dfrE, and adaptation driving mobile elements. bioRxiv 2020. [CrossRef]

59. Lee, E.W.; Chen, J.; Huda, M.N.; Kuroda, T.; Mizushima, T.; Tsuchiya, T. Functional cloning and expression of emeA, and characterization of EmeA, a multidrug efflux pump from Enterococcus faecalis. Biol. Pharm. Bull. 2003, 26, 266-270. [CrossRef] [PubMed]

60. Lerma, L.L.; Benomar, N.; Valenzuela, A.S.; Muñoz, M.d.C.C.; Gálvez, A.; Abriouel, H. Role of EfrAB efflux pump in biocide tolerance and antibiotic resistance of Enterococcus faecalis and Enterococcus faecium isolated from traditional fermented foods and the effect of EDTA as EfrAB inhibitor. Food Microbiol. 2014, 44, 249-257. [CrossRef]

61. Singh, K.V.; Weinstock, G.M.; Murray, B.E. An Enterococcus faecalis ABC homologue (Lsa) is required for the resistance of this species to clindamycin and quinupristin-dalfopristin. Antimicrob. Agents Chemother. 2002, 46, 1845-1850. [CrossRef]

62. Akhtar, M.; Hirt, H.; Zurek, L. Horizontal transfer of the tetracycline resistance gene tetM mediated by pCF10 among Enterococcus faecalis in the house fly (Musca domestica L.) alimentary canal. Microb. Ecol. 2009, 58, 509-518. [CrossRef]

63. Malbruny, B.; Werno, A.M.; Murdoch, D.R.; Leclercq, R.; Cattoir, V. Cross-resistance to lincosamides, streptogramins A, and pleuromutilins due to the lsa (C) gene in Streptococcus agalactiae UCN70. Antimicrob. Agents Chemother. 2011, 55, 1470-1474. [CrossRef]

64. Haubert, L.; da Cunha, C.E.P.; Lopes, G.V.; da Silva, W.P. Food isolate Listeria monocytogenes harboring tetM gene plasmidmediated exchangeable to Enterococcus faecalis on the surface of processed cheese. Food Res. Int. 2018, 107, 503-508. [CrossRef] 
65. Gabashvili, E.; Osepashvili, M.; Koulouris, S.; Ujmajuridze, L.; Tskhitishvili, Z.; Kotetishvili, M. Phage Transduction is Involved in the Intergeneric Spread of Antibiotic Resistance-Associated bla CTX-M, mel, and tetM Loci in Natural Populations of Some Human and Animal Bacterial Pathogens. Curr. Microbiol. 2020, 77, 185-193. [CrossRef] [PubMed]

66. Costa, Y.; Galimand, M.; Leclercq, R.; Duval, J.; Courvalin, P. Characterization of the chromosomal aac (6')-Ii gene specific for Enterococcus faecium. Antimicrob. Agents Chemother. 1993, 37, 1896-1903. [CrossRef] [PubMed]

67. Isnard, C.; Malbruny, B.; Leclercq, R.; Cattoir, V. Genetic basis for in vitro and in vivo resistance to lincosamides, streptogramins A, and pleuromutilins (LSAP phenotype) in Enterococcus faecium. Antimicrob. Agents Chemother. 2013, 57, 4463-4469. [CrossRef] [PubMed]

68. Singh, K.V.; Malathum, K.; Murray, B.E. Disruption of an Enterococcus faecium species-specific gene, a homologue of acquired macrolide resistance genes of staphylococci, is associated with an increase in macrolide susceptibility. Antimicrob. Agents Chemother. 2001, 45, 263-266. [CrossRef]

69. Reynolds, E.D.; Cove, J.H. Resistance to telithromycin is conferred by msr (A), msrC and msr (D) in Staphylococcus aureus. J. Antimicrob. Chemother. 2005, 56, 1179-1180. [CrossRef]

70. Flórez, A.B.; de Los Reyes-Gavilán, C.G.; Wind, A.; Mayo, B.; Margolles, A. Ubiquity and diversity of multidrug resistance genes in Lactococcus lactis strains isolated between 1936 and 1995. FEMS Microbiol. Lett. 2006, 263, 21-25. [CrossRef]

71. Esaiassen, E.; Hjerde, E.; Cavanagh, J.P.; Simonsen, G.S.; Klingenberg, C. Bifidobacterium bacteremia: Clinical characteristics and a genomic approach to assess pathogenicity. J. Clin. Microbiol. 2017, 55, 2234-2248. [CrossRef]

72. Heuer, H.; Krögerrecklenfort, E.; Wellington, E.; Egan, S.; Van Elsas, J.; Van Overbeek, L.; Collard, J.M.; Guillaume, G.; Karagouni, A.; Nikolakopoulou, T.; et al. Gentamicin resistance genes in environmental bacteria: Prevalence and transfer. FEMS Microbiol. Ecol. 2002, 42, 289-302. [CrossRef]

73. Zhang, X.Y.; Ding, L.J.; Fan, M.Z. Resistance patterns and detection of aac (3)-IV gene in apramycin-resistant Escherichia coli isolated from farm animals and farm workers in northeastern of China. Res. Vet. Sci. 2009, 87, 449-454. [CrossRef]

74. Paterson, D.L.; Bonomo, R.A. Extended-spectrum $\beta$-lactamases: A clinical update. Clin. Microbiol. Rev. 2005, 18, 657-686. [CrossRef]

75. Rawat, D.; Nair, D. Extended-spectrum $\beta$-lactamases in Gram Negative Bacteria. J. Glob. Infect. Dis. 2010, 2, 263. [CrossRef] [PubMed]

76. Jeong, S.H.; Bae, I.K.; Lee, J.H.; Sohn, S.G.; Kang, G.H.; Jeon, G.J.; Kim, Y.H.; Jeong, B.C.; Lee, S.H. Molecular characterization of extended-spectrum beta-lactamases produced by clinical isolates of Klebsiella pneumoniae and Escherichia coli from a Korean nationwide survey. J. Clin. Microbiol. 2004, 42, 2902-2906. [CrossRef] [PubMed]

77. Lahlaoui, H.; Dahmen, S.; Moussa, M.; Omrane, B. First detection of TEM-116 extended-spectrum $\beta$-lactamase in a Providencia stuartii isolate from a Tunisian hospital. Indian J. Med Microbiol. 2011, 29, 258. [CrossRef] [PubMed]

78. Lin, T.L.; Tang, S.I.; Fang, C.T.; Hsueh, P.R.; Chang, S.C.; Wang, J.T. Extended-spectrum $\beta$-lactamase genes of Klebsiella pneumoniae strains in Taiwan: Recharacterization of shv-27, shv-41, and tem-116. Microb. Drug Resist. 2006, 12, 12-15. [CrossRef] [PubMed]

79. Vieira, J.; Messing, J. The pUC plasmids, an M13mp7-derived system for insertion mutagenesis and sequencing with synthetic universal primers. Gene 1982, 19, 259-268. [CrossRef]

80. Koncan, R.; Valverde, A.; Morosini, M.I.; García-Castillo, M.; Cantón, R.; Cornaglia, G.; Baquero, F.; del Campo, R. Learning from mistakes: Taq polymerase contaminated with $\beta$-lactamase sequences results in false emergence of Streptococcus pneumoniae containing TEM. J. Antimicrob. Chemother. 2007, 60, 702-703. [CrossRef] [PubMed]

81. Martínez, J.L.; Coque, T.M.; Baquero, F. What is a resistance gene? Ranking risk in resistomes. Nat. Rev. Microbiol. 2015, 13, 116-123. [CrossRef] [PubMed]

82. CDC. Outpatient Antibiotic Prescriptions; CDC: Atlanta, GA, USA, 2018.

83. WHO. WHO Report on Surveillance of Antibiotic Consumption: 2016-2018 Early Implementation; WHO: Geneva, Switzerland, 2019.

84. Nishino, K.; Yamaguchi, A. Role of histone-like protein H-NS in multidrug resistance of Escherichia coli. J. Bacteriol. 2004, 186, 1423-1429. [CrossRef]

85. Founou, L.L.; Allam, M.; Ismail, A.; Essack, S.Y. Enterococcus faecalis ST21 harbouring Tn6009 isolated from a carriage sample in South Africa. S. Afr. Med J. 2021, 111, 98-99. [CrossRef]

86. Ammor, M.S.; Florez, A.B.; Álvarez-Martín, P.; Margolles, A.; Mayo, B. Analysis of tetracycline resistance tet (W) genes and their flanking sequences in intestinal Bifidobacterium species. J. Antimicrob. Chemother. 2008, 62, 688-693. [CrossRef]

87. Duranti, S.; Lugli, G.A.; Mancabelli, L.; Turroni, F.; Milani, C.; Mangifesta, M.; Ferrario, C.; Anzalone, R.; Viappiani, A.; van Sinderen, D.; et al. Prevalence of antibiotic resistance genes among human gut-derived bifidobacteria. Appl. Environ. Microbiol. 2017, 83, e02894-16. [CrossRef]

88. Kazimierczak, K.A.; Flint, H.J.; Scott, K.P. Comparative analysis of sequences flanking tet (W) resistance genes in multiple species of gut bacteria. Antimicrob. Agents Chemother. 2006, 50, 2632-2639. [CrossRef]

89. Ramirez, M.S.; Tolmasky, M.E. Amikacin: Uses, resistance, and prospects for inhibition. Molecules 2017, 22, 2267. [CrossRef] [PubMed]

90. Werner, G.; Hildebrandt, B.; Witte, W. The newly described msrC gene is not equally distributed among all isolates of Enterococcus faecium. Antimicrob. Agents Chemother. 2001, 45, 3672-3673. [CrossRef] [PubMed] 
91. Overdevest, I.; Willemsen, I.; Rijnsburger, M.; Eustace, A.; Xu, L.; Hawkey, P.; Heck, M.; Savelkoul, P.; Vandenbroucke-Grauls, C.; van der Zwaluw, K.; et al. Extended-spectrum $\beta$-lactamase genes of Escherichia coli in chicken meat and humans, The Netherlands. Emerg. Infect. Dis. 2011, 17, 1216. [CrossRef]

92. Kamaruzzaman, E.A.; Abdul Aziz, S.; Bitrus, A.A.; Zakaria, Z.; Hassan, L. Occurrence and Characteristics of Extended-Spectrum $\beta$-Lactamase-Producing Escherichia coli from Dairy Cattle, Milk, and Farm Environments in Peninsular Malaysia. Pathogens 2020, 9, 1007. [CrossRef] [PubMed]

93. Naidoo, Y.; Valverde, A.; Cason, E.D.; Pierneef, R.E.; Cowan, D.A. A clinically important, plasmid-borne antibiotic resistance gene ( $\beta$-lactamase TEM-116) present in desert soils. Sci. Total. Environ. 2020, 719, 137497. [CrossRef]

94. Sharma, P.; Haycocks, J.R.; Middlemiss, A.D.; Kettles, R.A.; Sellars, L.E.; Ricci, V.; Piddock, L.J.; Grainger, D.C. The multiple antibiotic resistance operon of enteric bacteria controls DNA repair and outer membrane integrity. Nat. Commun. 2017, 8, 1-12. [CrossRef] [PubMed]

95. Panthee, S.; Paudel, A.; Hamamoto, H.; Ogasawara, A.A.; Iwasa, T.; Blom, J.; Sekimizu, K. Complete genome sequence and comparative genomic analysis of Enterococcus faecalis EF-2001, a probiotic bacterium. Genomics 2021, 113, 1534-1542. [CrossRef]

96. Bozdogan, B.; Galopin, S.; Gerbaud, G.; Courvalin, P.; Leclercq, R. Chromosomal aadD2 encodes an aminoglycoside nucleotidyltransferase in Bacillus clausii. Antimicrob. Agents Chemother. 2003, 47, 1343-1346. [CrossRef]

97. Courvalin, P. Antibiotic resistance: The pros and cons of probiotics. Dig. Liver Dis. 2006, 38, S261-S265. [CrossRef]

98. Gaeta, N.C.; Bean, E.; Miles, A.M.; de Carvalho, D.U.O.G.; Alemán, M.A.R.; Carvalho, J.S.; Gregory, L.; Ganda, E. A cross-sectional study of dairy cattle metagenomes reveals increased antimicrobial resistance in animals farmed in a heavy metal contaminated environment. Front. Microbiol. 2020, 11, 590325. [CrossRef]

99. Shi, L.D.; Xu, Q.J.; Liu, J.Y.; Han, Z.X.; Zhu, Y.G.; Zhao, H.P. Will a Non-antibiotic Metalloid Enhance the Spread of Antibiotic Resistance Genes: The Selenate Story. Environ. Sci. Technol. 2020, 55, 1004-1014. [CrossRef] [PubMed]

100. Seol, D.; Jhang, S.Y.; Kim, H.; Kim, S.Y.; Kwak, H.S.; Kim, S.H.; Lee, W.; Park, S.; Kim, H.; Cho, S.; et al. Accurate and strict identification of probiotic species based on coverage of whole-metagenome shotgun sequencing data. Front. Microbiol. 2019, 10, 1683. [CrossRef] [PubMed] 